\title{
The Contractility and Performance of the Preterm Left Ventricle before and after Early Patent Ductus Arteriosus Occlusion in Surfactant- Treated Lambs
}

\author{
B. G. BAYLEN, H. OGATA, K. OGUCHI, M. IKEGAMI, H. JACOBS, A. JOBE, AND \\ G. C. EMMANOUILIDES \\ University of California Los Angeles, School of Medicine, Harbor-UCLA Medical Center, Department of \\ Pediatrics, Torrance, California 90509
}

\begin{abstract}
The influence of left-right ductal shunting on early hemodynamic responses, namely left ventricular performance, contractility, and systemic perfusion was evaluated in nine preterm lambs (120 days gestational age) treated with surfactant. Blood gases were maintained in the physiological range using mechanical ventilation; hemodynamic and blood flow measurements (radionuclide labeled microspheres) were obtained before and after occlusion of the patent ductus arteriosus with a catheter balloon. The mean left-right ductal shunt before occlusion (1.2 h postnatal age) was $59 \pm 11 \% \mathrm{SD}$. Left ventricular output was increased in all lambs with PDA (pre: $306 \pm$ 106 versus post: $155 \pm 31 \mathrm{ml} / \mathrm{min} / \mathrm{kg} ; p<0.001)$; effective systemic blood flow and organ blood flows did not change. The left ventricle end-diastolic volume was increased in all and decreased following ductal occlusion (pre: $2.0 \pm 0.4$ verus post: $1.5 \pm 0.2 \mathrm{ml} / \mathrm{kg} ; p<0.01$ ). Cardiac rate, ejection fraction, and contractility (peak dP/dt) did not change. Right-left ductal shunting was not detected in six similarly treated lambs. Thus, during the 1 st $h$ of life the hemodynamic profile of preterm lambs with patent ductus arteriosus was characterized by large magnitude left-right shunt and a "high" cardiac output state sufficient to maintain unchanged systemic perfusion. The increased left ventricle output was accomplished by increasing end-diastolic volume (Frank-Starling mechanism), but left ventricle contractility remained unchanged. We speculate that the preterm left ventricle may be unable to sustain the high level of pump performance and contractility required to compensate for the ductal "steal" of systemic blood flow. (Pediatr Res 19: 1053-1058, 1985)
\end{abstract}

\section{Abbreviations}

PDA, patent ductus arteriosus

$L V$, left ventricle

The persistently PDA represents a major challenge for the preterm cardiovascular system undergoing the fetal transition to extrauterine life. It has been well demonstrated that left-right

Received January 30, 1985; accepted May 20, 1985.

Reprint address Barry G. Baylen, M.D., Department of Pediatrics, Division of Pediatric Cardiology, Harbor-UCLA Medical Center, 100 West Carson Street, Torrance, CA 90509.

Supported by Grants 590 GL03 and 676 IG from the American Heart Associaton, Greater Los Angeles Affiliate and NIH Grant HD 12714. ductal shunting adversely affects the cardiopulmonary status of such infants (1-5). Recent advances using assisted ventilation and surfactant therapy have made it possible to study early postnatal cardiovascular adaptation in premature animals under acceptable physiological conditions $(6,7)$. Early cardiovascular adjustments to left-right ductal shunting have been infrequently studied under such circumstances $(8,9)$. Various studies suggest that the increased metabolic and oxygen requirements of the term newborn are provided by increasing LV performance and "contractile state" (10-12). However, it is unclear whether the immature LV of the preterm has sufficient "reserve" capacity to undergo these transitional circulatory adjustments, particularly when additional pathological LV volume load and left-right ductal shunting are present $(10,13-15)$.

A prior study of 2-h-old preterm lambs (120-124 days gestational age) with left-right ductal shunting suggested that the LV was unable to compensatorily increase cardiac output or maintain systemic perfusion (8). However, it was unclear whether a "deterioration" of cardiovascular performance had occurred during the first hours after birth or whether the findings represented the limited response of the immature LV. The purpose of this study is to describe earlier alterations of LV pump performance and contractility and the distribution of systemic blood flow associated with left-right ductus arteriosus shunting in surfactanttreated preterm lambs.

\section{EXPERIMENTAL PREPARATION}

Fifteen lambs were delivered by cesarean section of date-bred, Western, mixed breed ewes at 0.8 gestational age (120-124 days). The ewes were premedicated with intramuscular injection of ketamine $(800 \mathrm{mg})$ and atropine sulfate $(3 \mathrm{mg})$, and surgery was performed under spinal anesthesia. The head and neck of each lamb was delivered and a $4.5 \mathrm{~mm}$ endotracheal tube was immediately secured in the trachea by tracheotomy under local anesthesia. Each lamb was treated with a 15-ml suspension containing natural sheep surfactant $(50 \mathrm{mg}$ lipid $/ \mathrm{kg}$ ) instilled into the endotracheal tube before the first breath. The surfactant was isolated from the lavaged lung fluid of adult ewes and characterized as previously described $(7,16)$. Delivery was completed and the lambs were placed on a pressure limited ventilator (Sechrist) with settings of 30 breaths/min, a positive end-expiratory pressure of $2 \mathrm{~cm} \mathrm{H}_{2} \mathrm{O}$, a peak inspiratory pressure of 28 $\mathrm{cm} \mathrm{H}_{2} \mathrm{O}$, and an inspiratory time of $1 \mathrm{~s}$. A no. $5 \mathrm{~F}$ catheter was placed in the distal thoracic aorta through an umbilical artery, and the lambs were paralyzed with a single dose of intravenous pancuronium bromide $(0.1 \mathrm{mg} / \mathrm{kg})$. Rectal temperature was maintained at $38-39^{\circ} \mathrm{C}$ using a heating pad and heat lamps. 


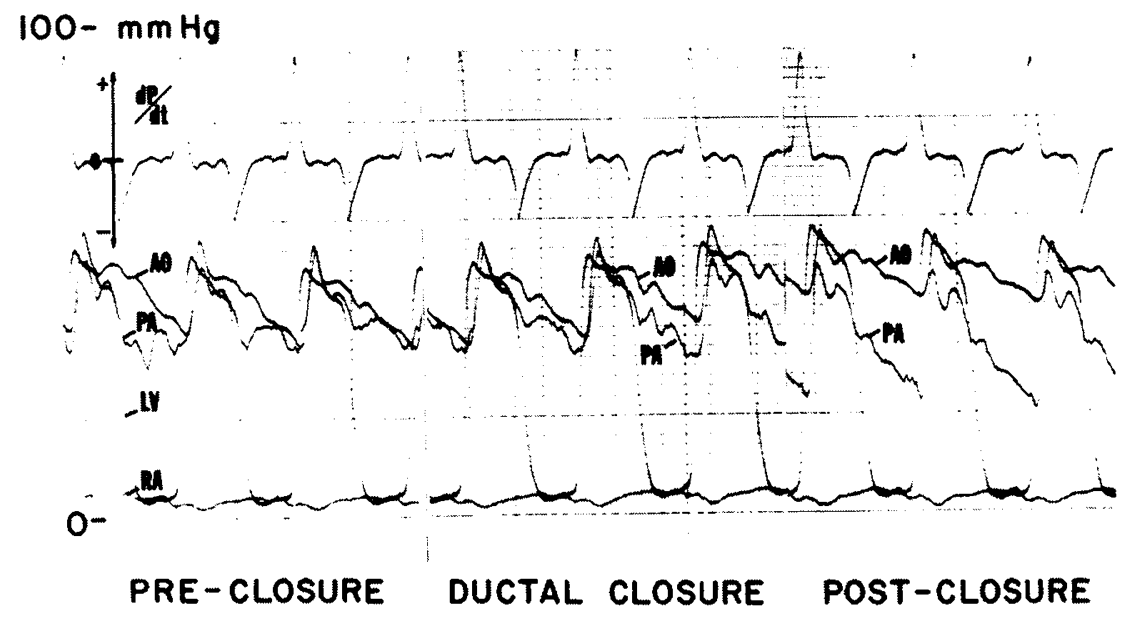

Fig. 1. Composite of instantaneous pressure recordings before, during, and after ductus arteriosus occlusion (catheter ports are proximal to balloon). Full scale is $0-100 \mathrm{~mm} \mathrm{Hg}$ and $\mathrm{dP} / \mathrm{dt}$ is $300 \mathrm{~mm} \mathrm{Hg} / \mathrm{s} /$ division. Before occlusion peak aortic ( $\mathrm{Ao}$ ), systoic and LV pressures are slightly greater than peak systolic pulmonary arterial $(P A)$ pressure. Following ductal occlusion systemic pressures rise minimally and pulmonary arterial pressures fall. There is no obstruction or pressure gradient between LV transducer-tipped catheter and thoracic Ao.

Blood losses were replaced with freshly collected, anticoagulated, filtered, maternal blood. Peak inspiratory pressures, rates and inspired oxygen concentrations were adjusted to maintain arterial blood gas tensions $\left(\mathrm{PO}_{2} 40-80 \mathrm{~mm} \mathrm{Hg}, \mathrm{PCO}_{2} 30-40 \mathrm{~mm} \mathrm{Hg}\right)$ and arterial pH (7.30-7.45), as assessed by frequent measurements (BMS-III Blood Micro System, Radiometer, Copenhagen). The absence of pneumothorax during the study was confirmed by fluoroscopy of the chest, review of cineangiocardiograms, and postmortem examination of the lungs.

\section{CATHETER PLACEMENT}

The tracheotomy incision was extended 1-2 cm laterally (under local anesthesia) and the lambs were catheterized using fluoroscopy and pressure monitoring (Fig. 1). In nine lambs (group I) two fluid-filled catheters were placed into the right jugular vein and advanced to the right atrium (no. $3.5 \mathrm{~F}$ polyvinyl catheter, Argyle, St. Louis, MO) and to the main pulmonary artery (no. 5F flow-directed balloon angiography catheter, Edwards Laboratories, Santa Ana, CA): A no. $5 \mathrm{~F}$ polyvinyl catheter was advanced into the umbilical artery to the descending thoracic aorta. A no. 5F transducer-tipped catheter (Millar Instruments, Inc., Houston, TX) was placed in the right carotid artery and advanced to the apex of the LV. A no. 4F balloon angiography catheter (Edwards Laboratories) was advanced into the umbilical vein through the foramen ovale to the left ventricle. In six additional lambs (group II), the catheterization was modified in the following manner in order to detect potential right-left ductal shunting. In these lambs a venous catheter was placed in the right ventricle, and a no. $3.5 \mathrm{~F}$ catheter was placed via the right carotid artery into the LV (the umbilical venous and transducertipped LV catheters were not required). All procedures were carried out in accordance with standards of the American Physiological Society.

\section{MEASUREMENTS AND CALCULATIONS}

Pressures were recorded using a Hewlett-Packard multichannel photographic recorder, and pressure transducers were frequently zero'd and calibrated with a mercury manometer (Fig. 1). The transducer-tipped catheter was externally calibrated with a mercury manometer, and was periodically matched to in vivo pressure recordings from the fluid filled $\mathrm{LV}$ angio-catheter. The rate of rise, or first derivative of $\mathrm{LV}$ pressure $(\mathrm{dP} / \mathrm{dt})$, and the peak rate of rise (peak $\mathrm{dP} / \mathrm{dt}$ ) were inscribed using a Hewlett-Packard derivative amplifier. LV cardiac output and the distribution of organ blood flows were measured by a 15-s infusion into the LV of $15-\mu \mathrm{m}$ diameter, radionuclide labeled microspheres suspended in $5 \mathrm{ml}$ of maternal blood $\left({ }^{57} \mathrm{Co},{ }^{46} \mathrm{Sc},{ }^{113} \mathrm{Sn}\right.$, New England Nuclear, Boston, MA). Concurrent with each injection of microspheres, a reference sample was withdrawn at a rate of $6 \mathrm{ml} / \mathrm{min}$ for $2 \mathrm{~min}$ from the descending thoracic aorta (position confirmed fluoroscopically) (17); the volume withdrawn was simultaneously replaced with maternal blood. All microspheres were assumed to be trapped on the first pass through the capillary beds. Enough microspheres were injected to ensure adequate distribution and accurate flow measurements in organs with the lowest blood flow (17). The adequacy of the withdrawal of a single reference sample from the descending thoracic aorta of lambs has been documented $(9,17)$. However, others suggested that incomplete mixing after injection of microspheres into the LV was associated with small discrepancies (mean $11 \%$ ) of absolute blood flows calculated from simultaneous ascending and descending aortic samples (18). These discrepancies may apply particularly to the calculation of proximal organ flows, such as myocardial blood flow; consequently, this study emphasizes the change rather than absolute values for myocardial blood flow before and after ductal occlusion.

The lambs were sacrificed under general anesthesia (pentobarbitol overdose) and the organs were removed and weighed; the amount of each radioisotope was counted in a multichannel $\gamma$ spectrometer (CG-30, Intertechnique, Fairfield, NJ). Smaller organs were counted directly in counting vials; larger organs were individually ashed and then counted. The LV cardiac output ( $\mathrm{ml} / \mathrm{min} / \mathrm{kg}$ body weight), its percent distribution, and organ blood flows $(\mathrm{ml} / \mathrm{min} / \mathrm{g})$ were calculated from the amounts of total microspheres injected, the microspheres in each organ, and the reference sample (17). The magnitude of left-to-right ductal shunt was expressed as a percentage of the total LV cardiac output diverted to the lungs. A maximum potential bronchial blood flow was assumed to be $10 \%$ of the total pulmonary blood flow (left ventricular output) after ductal occlusion (18). The bronchial blood flow was deducted from the total amount of LV output diverted to the lungs, and the remaining flow to the lungs was considered the contribution of left-to-right ductal shunt. The assumption of a maximum bronchial flow leads to a conservative estimate of left-right ductal shunting (18). The "effective" systemic blood flow was expressed as LV cardiac output minus the calculated left-to-right ductal shunt. (The "effective" systemic flow includes the bronchial blood flow.) Appreciable right-to-left shunts were not present during the first hours of life in prior studies using this model (9). We assumed the absence of substan- 
Table 1. Arterial blood gases, $p H$, and hemodynamics before and after ductus arteriosus occlusion

\begin{tabular}{|c|c|c|c|c|c|c|c|c|c|c|c|}
\hline & \multirow{2}{*}{$\begin{array}{l}\text { Age } \\
\text { (h) }\end{array}$} & \multirow[b]{2}{*}{$\mathrm{pH}$} & \multirow{2}{*}{$\begin{array}{c}\mathrm{pO}_{2} \\
(\mathrm{~mm} \mathrm{Hg})\end{array}$} & \multirow{2}{*}{$\begin{array}{c}\mathrm{pCO}_{2} \\
(\mathrm{~mm} \mathrm{Hg}) \\
\end{array}$} & \multirow{2}{*}{$\begin{array}{c}\text { LV cardiac } \\
\text { output } \\
\left(\mathrm{ml} \cdot \mathrm{min}^{-1}\right. \\
\mathrm{kg}^{-1} \text { ) }\end{array}$} & \multirow{2}{*}{$\begin{array}{c}\text { Lt-Rt } \\
\text { shunt } \\
(\%)\end{array}$} & \multirow{2}{*}{$\begin{array}{c}\text { Qs } \\
\text { "effective" } \\
\left(\mathrm{ml} \cdot \mathrm{min}^{-1} \text {. }\right. \\
\left.\mathrm{kg}^{-1}\right)\end{array}$} & \multicolumn{2}{|c|}{ Ao pressure $(\mathrm{mm} \mathrm{Hg})$} & \multicolumn{2}{|c|}{ PA pressure $(\mathrm{mm} \mathrm{Hg})$} \\
\hline & & & & & & & & Sys/dias & Mean & Sys/dias & Mean \\
\hline Occluded & $1.6 \pm 0.2$ & $7.31 \pm 0.06 \dagger$ & $38 \pm 11 \dagger$ & $39 \pm 6$ & $155 \pm 31 \ddagger$ & & & $47 \pm 9 / 35 \pm$ & $(40 \pm 9)$ & $37 \pm 6 / 18 \pm 2 \S$ & $(26 \pm 3 \S)$ \\
\hline
\end{tabular}

$*$ Values are expressed as mean $\pm \mathrm{SD}(n=9) ; \dagger p<0.05 ; \neq p<0.001 ; \S p<0.01$.

Abbreviations: Ao, aortic; Lt-Rt, left-to-right; LV, left ventricular; PA, pulmonary artery; Qs, systemic blood flow.

Table 2. Organ blood flows before and after occlusion of the patent ductus arteriosus

\begin{tabular}{lcccccc}
\hline & Carcass & Heart & Brain & Gastrointestinal & Kidney & Liver \\
\hline Preclosure* & $0.09 \pm 0.04$ & $2.25 \pm 1.23$ & $0.23 \pm 0.07$ & $0.30 \pm 0.16$ & $0.64 \pm 0.22$ & $0.28 \pm 0.24$ \\
Pccluded & $0.10 \pm 0.03$ & $2.79 \pm 1.10$ & $0.32 \pm 0.15$ & $0.32 \pm 0.12$ & $0.51 \pm 0.28$ & $0.30 \pm 0.16$ \\
\hline
\end{tabular}

* Values expressed as mean $\pm \mathrm{SD}\left(\mathrm{ml} \cdot \mathrm{min}^{-1} \cdot \mathrm{g}^{-1}\right)$.

tial right-left atrial shunting in this model, and pulmonary blood flow was considered equal to LV cardiac output. Because labeled microspheres were infused into the $\mathrm{LV}$, the contribution of potential right-to-left atrial shunt would be included in the calculated LV cardiac outputs and organ blood flows (18); similarly right-to-left atrial shunting would not alter the calculated angiographic LV volumes (18, 19). However, right-to-left ductal shunting may occur as peak pulmonary arterial systolic pressure approaches systemic levels (20). Such a right-to-left ductal shunt would "dilute" the thoracic reference sample, and the calculated LV output and organ blood flows would be overestimated. Consequently, in six lambs (group II) the catheterization and protocol were specifically modified (as described) to detect potential right-to-left ductal shunting. In these, an injection of microspheres into the right ventricle preceeded the microsphere injection into the LV before ductal occlusion. The remaining experimental circumstances were maintained essentially equivalent to those for group I lambs.

\section{CINEANGIOCARDIOGRAPHY}

Cine left ventriculograms were obtained without disturbing the lambs approximately $5 \mathrm{~min}$ after each injection of radionuclide-labeled microspheres. The lambs lay in a left lateral position, which provides a maximum projection of the LV axis (21). Dilute contrast (1 ml/kg Renografin-60, Squibb, New Brunswick, $\mathrm{NJ}$ ) was injected through the LV catheter, and cineangiocardiograms were recorded on $16-\mathrm{mm}$ film at a rate of 60 frames/s. Volumes were calculated using the single plane area-length method (19). The mean LV end-systolic and enddiastolic volumes $(\mathrm{ml} / \mathrm{kg}$ ) and ejection fraction (\%) were calculated from two or three nearly consecutive cardiac cycles (extrasystolic and post-extrasystolic beats were excluded). The calculated volumes were then corrected using regression equations derived from comparisons of volumes calculated from projected 16-mm cine frames of preterm and term lamb LV casts with their corresponding water displacement volumes (21). Cineangiocardiography provides good estimates of $\mathrm{LV}$ volumes and function in small lambs (22). We previously demonstrated a $12 \%$ mean difference between such calculated volumes and their actual water displacement volumes (21). However, the calculation of cardiac output is limited since any error of the estimated stroke volume is multiplied by the cardiac rate. Consequently, the cardiac outputs and organ blood flows reported herein were estimated using radionuclide-labeled microspheres.

\section{EXPERIMENTAL PROTOCOL}

We obtained measurements before and after occlusion of the ductus arteriosus in order to evaluate the influence of left-toright ductal shunting on LV performance, contractility and organ blood flows. The catheters were placed within 50 min after birth, and each lamb was allowed to stabilize for approximately $20 \mathrm{~min}$ before baseline measurements were obtained. In nine lambs (group I) baseline blood gases, $\mathrm{pH}$, and cardiovascular pressures were measured. Radionuclide labeled microsphere blood flow studies and cine left ventriculography were performed. The flowdirected balloon angiographic catheter was then advanced under fluoroscopic guidance from the main pulmonary artery into the lumen of the ductus arteriosus. Occlusion was accomplished as previously described and confirmed by fluoroscopy, continuous pressure measurements, and review of cineangiograms (Fig. 1) (8). Soon after closure of the ductus (mean $7 \pm 10 \mathrm{~min}$ ), all measurements were repeated.

Six lambs (group II) underwent additional studies for detection of right-to-left ductal shunting (18); in these, specific radionuclide labeled microspheres were injected into the right ventricle. Radionuclide labeled microspheres were than injected into the LV (approximately 5-7 min) as in group I. Cineangiocardiography was obtained before and following ductal occlusion (radionuclide-labeled microsphere systemic blood flow studies were not obtained following occlusion).

\section{STATISTICS}

Measurements obtained before and after ductal occlusion were analyzed statistically by paired $t$ test and measurements from the different groups were compared using Students unpaired $t$ test. The level of significance was $p<0.05$ (two-tailed test). The data are reported as mean $\pm \mathrm{SD}$.

\section{RESULTS}

The arterial blood gases and hemodynamic and blood flow data for the group I lambs are shown in Tables 1 and 2 and Figure 2. The baseline measurements were obtained $1.2 \pm 0.2 \mathrm{~h}$ after birth, and measurements after ductal occlusion were obtained $1.6 \pm 0.2 \mathrm{~h}$ after birth. Although arterial $\mathrm{po}_{2}$ and $\mathrm{pH}$ changed significantly, they remained within the physiological range indicating acceptable ventilatory and acid-base balance during the study interval (Table 1).

The ductus arteriosus was restrictive (pulmonary peak systolic $<0.9$ aortic systolic pressure) in five of the nine (group I) lambs before ductal occlusion. The mean left-to-right ductal shunt was $59 \pm 11 \%$ of the left ventricular cardiac output and negligible shunting $(4.5 \%)$ was detected after ductal occlusion (Table 1). The calculated mean pulmonary to systemic blood flow ratio before ductal occlusion was 2.4:1. The LV output was increased in all lambs with PDA and decreased significantly from 306 to $155 \mathrm{ml} / \mathrm{min} / \mathrm{kg}$ after ductal occlusion. The "effective" systemic blood flow and organ blood flows did not change since the LV 


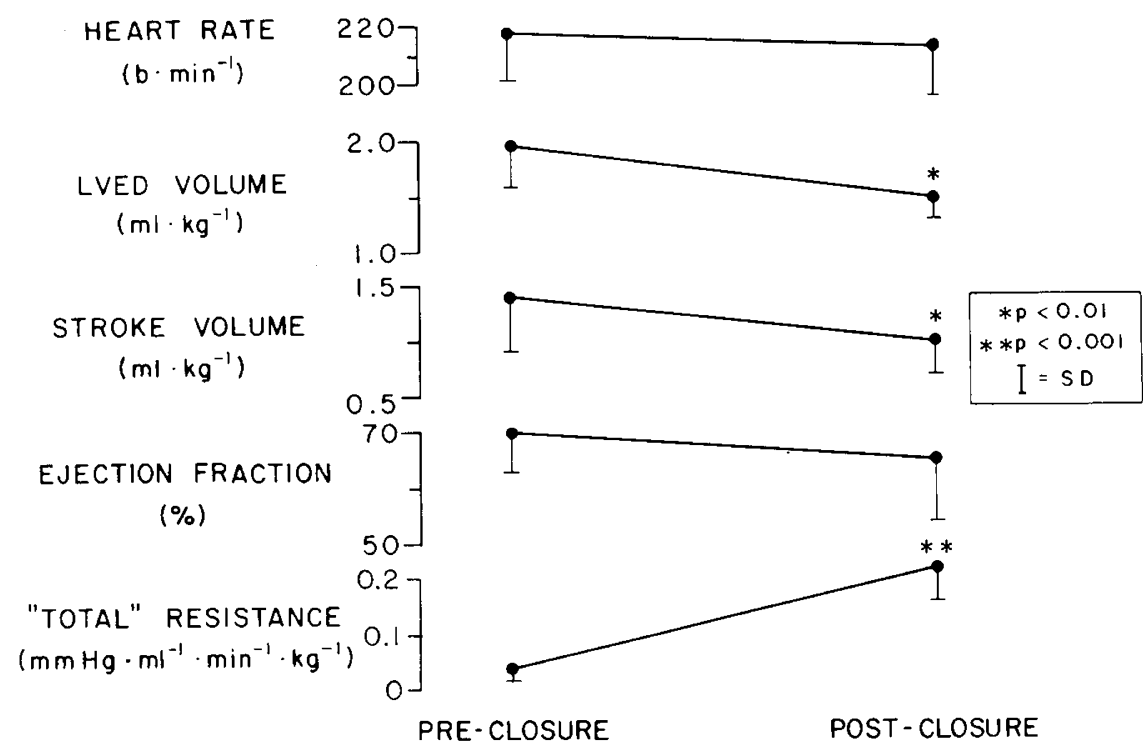

Fig. 2. Left ventricular performance and related variables before and after occlusion of the ductus arteriosus. Prior to ductal occlusion increased stroke volume (and cardiac output) was accomplished primarily by increasing LV end-diastolic volume since ejection fraction and cardiac rate were unchanged. The relatively good LV performance may be in part related to the marked reduction of impedance (total resistance) to left ventricular ejection.

output increased in proportion to the volume of left-to-right ductal shunting (Table 2).

In all lambs the increased LV cardiac output was accomplished at significantly greater angiographic mean LV end-diastolic volume and stroke volume; the mean LV end-diastolic volume fell from $2.0 \pm 0.4$ to $1.5 \pm 0.2 \mathrm{ml} / \mathrm{kg}$ after occlusion; stroke volume decreased from $1.43 \pm 0.36$ to $0.96 \pm 0.28(p<0.01)$; the heart rate and ejection fraction were uninfluenced by closure of the ductus arteriosus (Fig. 2).

The LV end-diastolic pressure did not change significantly (pre: $5 \pm 2$; post: $3 \pm 1 \mathrm{~mm} \mathrm{Hg}$ ), and the systemic arterial pressures did not change after ductal occlusion; however, pulmonary mean and diastolic pressures decreased significantly (Table 1). The contractility expressed by the isovolumic index, peak $\mathrm{dP} / \mathrm{dt}$ did not change. The peak $\mathrm{dP} / \mathrm{dt}$ before occlusion was $2250 \pm 233 \mathrm{~mm} \mathrm{Hg} / \mathrm{s}$ versus $2128 \pm 478$ following occlusion. The peak $\mathrm{dP} / \mathrm{dt}$ normalized for left ventricular end-diastolic volume $(1195 \pm 285 \mathrm{~mm} \mathrm{Hg} / \mathrm{s} / \mathrm{ml} / \mathrm{kg})$, did not change $(1416 \pm$ 497) (33). The "total systemic resistance" (systemic plus ductal resistance) before occlusion was much less than systemic resistance after occlusion $(0.04 \pm 0.02$ versus $0.25 \pm 0.07 \mathrm{~mm} \mathrm{Hg} /$ $\mathrm{ml} / \mathrm{min} / \mathrm{k} ; p<0.001$ ) (Fig. 2). Systemic vascular resistance (not including ductal resistance) was significantly increased before occlusion $(0.33 \pm 0.08$ versus $0.25 \pm 0.07 \mathrm{~mm} \mathrm{Hg} / \mathrm{ml} / \mathrm{min} / \mathrm{kg}$; $p<0.05)$. The pulmonary:systemic vascular resistance ratio increased from 0.34 to $0.63(p<0.001)$ after ductal occlusion.

The data from a prior study were compared with the present findings (8). The mean pulmonary:systemic vascular resistance ratio $(0.36 \pm 0.05)$ did not differ significantly from that measured in the current study $(0.34 \pm 0.12)$. However, ductus arteriosus resistance was significantly lower in the present study $(58 \pm 36$ versus $157 \pm 117 \mathrm{~mm} \mathrm{Hg} / \mathrm{liter} / \mathrm{kg} / \mathrm{min} ; p<0.008)$. Ductus arteriosus resistance (y) calculated from both studies was directly related to corresponding arterial $\mathrm{pAO}_{2}(\mathrm{x}) ;(\mathrm{y}=1.58 \mathrm{x}+7.1 ; r=$ $0.51 ; p=<0.01)$.

The group II lambs were studied under similar experimental conditions; the time of ductal oclusion $(1.1 \pm 0.1 \mathrm{~h})$, arterial $\mathrm{pH}$ $(7.45 \pm 0.05), \mathrm{po}_{2}(50 \pm 10 \mathrm{~mm} \mathrm{Hg})$, and $\mathrm{pCO}_{2}(28 \pm 3)$ did not differ significantly from group I (Table 1). Systemic mean arterial pressure $45 \pm 5 \mathrm{~mm} \mathrm{Hg}$ and pulmonary mean arterial pressure $41 \pm 6$ did not differ from that of group I. Pulmonary arterial peak systolic pressure was $90 \%$ of systemic arterial levels in five of six lambs and $80 \%$ of systemic in the remaining lamb. The mean left-to-right ductal shunt was somewhat lower $(30 \pm 9 \%$; $p<0.05)$ than in group I. Right-to-left ductal shunting was not detected by specific right ventricular microsphere injection in spite of the fact that pulmonary:systemic resistance ratio $(0.62 \pm$ $0.11)$ was significantly greater than in group I $(p<0.05)$. Heart rate $(195 \pm 35$ beats/min) did not change after ductal occlusion $(202 \pm 16)$. Left ventricular end-diastolic volume $(2.2 \pm 0.4 \mathrm{ml} /$ $\mathrm{kg})$ and stroke volume $(1.2 \pm 0.1 \mathrm{ml} / \mathrm{kg})$ were significantly increased $(p<0.01)$ and decreased in all lambs following occlusion (end-diastolic $1.5 \pm 0.2$, stroke volume $0.8 \pm 0.1 \mathrm{ml} / \mathrm{kg}$ ).

\section{DISCUSSION}

The lamb has been widely used as an experimental model for the study of cardiovascular physiology of the fetus and newborn. While the nature and pathophysiology of respiratory distress syndrome differs in the human and lamb, it is unclear whether similar developmentally related differences of cardiovascular performance exist (23). In this study preterm lambs delivered by cesarean section were optimally resuscitated and ventilated immediately at birth. Such idealized conditions are rarely encountered in the distressed human preterm infant. Early administration of surfactant did not influence cardiac performance unfavorably in this study or others (24). However, the magnitude of left-to-right ductal shunting may be greater than in human preterms with respiratory distress syndrome and PDA, since the improved oxygenation following administration of surfactant may be associated with a reduction of the pulmonary vascular resistance (9). These differences should be considered before extrapolating the observations of this study to the postnatal cardiovascular events occurring in human preterm infants.

In this study treatment of preterm lambs with natural sheep surfactant before the onset of respiration provided stable pulmonary function and facilitated the evaluation of cardiovascular physiology of preterm lambs. Although changes of arterial blood gases occurred, they remained within acceptable physiological limits enabling us to measure hemodynamic responses under satisfactory conditions. However, the relatively acute fall of arterial $\mathrm{pO}_{2}$ in the absence of a significant alteration of $\mathrm{pCO}_{2}$ following occlusion of the ductus arteriosus suggests either the presence of intracardiac right left shunt and/or a "mismatch" of pulmonary ventilation perfusion (Table 1 ). 
Using angiographic methods, conventional pressure recordings, and oximetry, right-to-left ductal shunting was demonstrated in some older infants and children with patent ductus arteriosus and pulmonary hypertension (20). The magnitude of right-to-left shunt was apparently small (occupying only the initial $12-18 \%$ of the "left-to-right systolic pressure gradient"), and occurred when pulmonary arterial pressure rise preceeded and was equivalent to peak systemic arterial pressure levels. Such right-to-left ductal shunting might lead to small overestimates of cardiac outputs calculated in this study, but would not account for the magnitude of increased cardiac output or the angiographically increased LV volumes observed in all of our lambs with PDA. Furthermore, we did not detect right-to-left ductal shunting in the group II lambs despite their significantly greater pulmonary:systemic vascular resistance ratios. In all these lambs pulmonary arterial peak systolic pressure was at least 0.8 peak systemic arterial pressure level. In a prior study of more hypoxic animals "rescued" with surfactant at mean times ranging from 47-120 minutes after birth, right-to-left shunting was not observed despite generally higher pulmonary:systemic vascular resistance ratios (mean $0.46-0.76$ ) than in the present study $(0.34)$ (9). Thus, the direction and magnitude of ductal shunting in the preterm lamb is apparently determined by the marked differences of systemic and pulmonary vascular resistances even though peak systolic arterial pressures are essentially equivalent $(3,25)$. Rudolph et al. (25) demonstrated continuous systolic-diastolic left-to-right shunting in canines with aortopulmonary prosthetic shunt. The similar pattern of left-to-right ductal shunting in the preterm lamb may be related to a relatively reduced pulmonary vasoconstrictor response postnatally (3).

In the present study we maintained the preterm lambs at generally lower arterial $\mathrm{PAO}_{2}(48 \pm 15$ torr; $p<0.1)$ than in a prior study (68 \pm 36 torr) in order to avoid potential ductal constriction (8); furthermore, we intended to simulate more closely conditions encountered in the neonatal ICU where low birth weight preterms are maintained at arterial $\mathrm{PAO}_{2}$ levels ranging from approximately $40-80$ torr. In this study the magnitude of left right dutal shunt $(59 \pm 11 \%)$ was significantly greater than in the prior study $(44 \pm 13 \% ; p<0.05)$, but the pulmonary:systemic vascular resistance ratios did not differ. Thus, the greater proportion of left-to-right shunt was apparently related to the significantly lower ductal resistance in the present study. Since an important primary postnatal stimulus for ductal constriction is oxygen, the relatively decreased ductal tone was most likely related to the maintenance of the lower arterial $\mathrm{PAO}_{2}$ (26). Furthermore the ductal resistance calculated from both studies was directedly related to corresponding arterial $\mathrm{PAO}_{2}$. Prior studies demonstrated maturationally related increasing responsiveness of isolated fetal lamb ductal strips to oxygen. However, at 130 days gestation ductal constriction began only when $\mathrm{pO}_{2}$ was raised to $150-200$ torr (26). In contrast, the ductus arteriosus of the intact newborn preterm lamb was capable of a wide range of constriction, and even functional closure, when exposed to relatively lower levels of arterial oxygenation (range 34-130 torr). The reasons for this apparently increased postnatal resposiveness in vivo are unclear. However, studies suggest that ductal responsiveness to a variety of prostaglandins and vasoactive agents in the intact fetus differed from responses of isolated ductal tissue (27). While the precise interaction between oxygen and these "modulating factors" remains unclear, it is apparent that ductal responsiveness to oxygen is augmented postnatally in the preterm lamb.

During the 1 st $h$ of life, lambs with PDA were capable of increasing LV output in proportion to the quantity of left-toright ductal shunt; consequently, the effective systemic and organ blood flows remained essentially unchanged. However, the latter imposed an approximate doubling of volume load on the left ventricle. The relatively higher cardiac output in lambs with PDA was comparable to that previously described in term newborn lambs, but was substantially higher than LV output ob- served in chronologically older lambs (1.9-2.6 h of age) with PDA and smaller left-to-right shunt; furthermore, similar surfactant-treated lambs with ductus arteriosus which was chronically occluded during the first 1-4 h after birth had even lower LV output (28). Thus, the higher cardiac output observed in the present study may in part be related to the larger proportion leftto-right ductal shunt through the lower resistance (larger caliber) PDA. Similarly, Rudolph et al. (25) observed an acutely increased cardiac rate and cardiac output upon the opening of an aortopulmonary prothesis in adult canines. However, these authors also noted that approximately $30 \%$ of the animals were unable to sustain increased cardiac output in face of left-to-right shunt, and termed this a "failure response"; in contrast with the present study, chronologically older preterm lambs with PDA were unable to compensatorily increase cardiac output in face of left-toright ductal shunt (8). Differences of cardiac performance in those lambs were unlikely related to deterioration of the experimental preparation since the acid base status was maintained at comparable levels and arterial $\mathrm{pO}_{2}$ was generally greater. Thus, the latter might represent an early manifestation of LV dysfunction or the "failure response"; however, other "systemic" factors (e.g. neuroendocrine, metabolic) might lead to such impaired $\mathrm{LV}$ responses as well.

Recently other authors demonstrated increased cardiac rate, increased LV dimensions and extent of shortening, and increased plasma catecholamines and contracitility (leftward displacement of the end-systolic pressure: volume relationship) in canines with acutely opened arteriovenous fistula (29); end-diastolic volume estimated from their data (LV dimensions cubed) increased approximately $21 \%$ and stroke volume increased $66 \%$. In contrast the cardiac rate and ejection fraction were essentially unchanged in our lambs with PDA; furthermore, the contractility as described by the peak $\mathrm{dP} / \mathrm{dt}$ and the LV systolic pressures and end-systolic volumes remained essentially unchanged in these lambs $(29,30)$. Therefore the compensatory increase of cardiac output was accomplished primarily at the expense of increasing $\mathrm{LV}$ end-diastolic volume and stroke volume, that is by the FrankStarling mechanism of the heart (Fig. 2). Because ejection fraction did not increase in the preterm lamb the augmentation of stroke volume was less than in the mature animal (approximately $42 \%$ ) and required a greater increase of $\mathrm{LV}$ end-diastolic volume (33\%). An increased ejection fraction would be expected in view of the markedly reduced impedance to $\mathrm{LV}$ ejection (i.e. $80 \%$ reduction of total vascular or systemic and ductal resistance) (31). Several studies suggest that isolated premature myocardium is less capable of generating tension than is that of the mature animal $(10,14,32)$. Consequently, the high cardiac output and the preservation of LV performance in preterm lambs with PDA may have been facilitated by the reduction of impedance to ejection into the lower resistance combined systemic and pulmonary vascular beds.

The contractility of the LV as characterized by the isovolumic phase index peak $\mathrm{dP} / \mathrm{dt}$ has not been previously reported for exteriorized preterm lambs. The LV peak $\mathrm{dP} / \mathrm{dt}$ was less than that previously reported for term lambs $(12,13)$. The relatively lower values observed in these preterm lambs may be related to the lower LV pressure developed, as well as to differences of "contractility" $(12,33)$. The peak $\mathrm{dP} / \mathrm{dt}$ is a volume sensitive isovolumic index of contractility, increasing with increasing LV preload; the LV end-diastolic volume was increased and other physiological variables known to influence this index remained unchanged in the lambs with PDA (33). In this study neither peak $\mathrm{dP} / \mathrm{dt}$ nor peak $\mathrm{dP} / \mathrm{dt}$ normalized to end-diastolic volume changed upon ductal occlusion (33). Thus, it appears that the LV was unable to augment contractility as expected in the presence of the left-to-right shunt and increasing volume load (31). It has been demonstrated that sympathetic innervation of the heart is incomplete at term and the newborn LV may be more dependent on and sensitive to circulating catecholamines $(14,34)$. Furthermore, it is apparent that the LV of the term 
newly born animal functions at a relatively increased level of contractility and is unable to augment contractility in response to $\beta$-adrenoceptor stimulation or during volume infusion (13, $15)$. These observations are consistent with the recent demonstration that increased secretion of catecholamines occurs immediately following birth (cord clamping) and the levels are greatest in preterm lambs $(35,36)$. In addition, following an initial catecholamine "surge," high circulating catecholamine levels are maintained during the first hours of life (36). Thus, the unchanged contractility we observed may represent a "maximal" level supported by the postnatal surge of circulating catecholamines. Under such circumstances the lambs might have a limited capacity to further increase contractility or improve LV ejection performance in the face of pathological LV volume load. Furthermore, postnatal LV performance and responses to pathological volume load might well vary during the first hours after birth, paralleling the exaggerated fluctuations of circulating catecholamines.

This study indicates that the preterm lamb with PDA is capable of relatively good "overall" pump performance during the $1 \mathrm{st} h$ of postnatal life. Despite relatively large magnitude left-to-right ductal shunting, the left ventricle was capable of mounting a compensatory increase of cardiac output sufficient to maintain unchanged systemic and organ blood flows. However, the increased cardiac output was maintained primarily at the expense of increasing left ventricular end-diastolic volume (Frank-Starling response). We speculate that the preterm LV may be unable to sustain the augmented level of performance required to compensate for the ductal "steal" of systemic blood flow. Under such circumstances a deterioration of LV pump performance or "contractility" would eventually lead to decreasing cardiac output and systemic hypoperfusion. This sequence of events might explain some pathological manifestations of the PDA syndrome of prematurity.

\section{REFERENCES}

1. Baylen BG, Emmanouilides GC 1984 Patent ductus arteriosus in the newborn. In: Gregory GA, Thibeault DW (eds) Neonatal Pulmonary Care. AppletonCentury-Crofts, East Norwalk CT (in press)

2. Fujiwara T, Maeta H, Morita T, Watanabe V, Chida S, Abe T 1980 Artificial surfactant therapy in hyaline membrane disease. Lancet 1:55-5.9

3. Hoffman JIE 1978 Factors affecting shunting and the development of heart failure. In: Rudolph AM, Heymann MA (eds) The ductus arteriosus. Report of the 75th Ross Conference on Pediatric Research. Ross Laboratories, Columbus, OH, pp 69-72

4. Jacob J, Gluck L, DiSessa T, Edwards D, Kulovich M, Kurlinski J, Merritt TA, Friedman WF 1980 The contribution of PDA in the neonate with severe RDS. J Pediatr 96:79-87

5. Mahoney L, Carnero V, Brett C, Heymann MA, Clyman RI 1982 Prophylactic indomethacin therapy for patent ductus arteriosus in very-low-birth weight infants. N Engl J Med 306:506-510

6. Adams FH, Towers B, Osher AB, Ikegami M, Fujiwara T, Nozaki M 1978 Effect of tracheal instillation of natural surfactant in premature lambs. Clinical and autopsy findings. Pediatr Res 12:841-848

7. Jobe A, Ikegami M, Glatz T, Yoshida Y, Diakomanolis E, Padbury J 1981 The duration and characteristics of treatment of premature lambs with natural surfactant. J Clin Invest 67:370-375

8. Baylen BG, Ogata H, Ikegami M, Jacobs H, Jobe A, Emmanouilides GC 1983 Left ventricular performance and regional blood flows before and after ductus arteriosus occlusion in premature lambs treated with surfactant. Circulation $67: 837-843$

9. Clyman RI, Jobe A, Heymann M, Ikegami M, Roman C, Payne B, Mauray F 1982 Increased shunt through the patent ductus arteriosus after surfactant therapy. J Pediatr 100:101-107
10. Klopfenstein SH, Rudolph AM 1978 Postnatal changes in the circulation and responses to volume loading in sheep. Circ Res 42:839-845

11. Lister G, Walter TK, Vermold HT, Dallman PR, Rudolph AM 1979 Oxygen delivery in lambs: Cardiosvascular and hematologic development. Am J Physiol 237:H668-675

12. Riemenschneider TA, Brenner RT, Mason DT 1981 Maturational changes in myocardial contractile state of newborn lambs. Pediatr Res 15:349-356

13. Baylen BG, Ogata H, Ikegami M, Jacobs H, Jobe A, Emmanouilides GC 1983 Frank-Starling performance and contractile state of the preterm and term left ventricle. Pediatr Res 17:108(abstr)

14. Friedman WF 1972 The intrinsic physiologic properties of the developing heart. Prog Cardiovasc Dis 15:87-111

15. Teitel D, Chin J, Rudolph A, Heymann M 1982 Postnatal changes in myocardial contractility. Pediatr Res 16:171(abstr)

16. Jobe A, Ikegami M, Jacobs H, Jones S 1984 Surfactant and pulmonary blood flow distributions following treatment of premature lambs with natural surfactant. J Clin Invest 73:848-856

17. Heymann MA, Payne BD, Hoffman JIE, Rudoph AM 1977 Blood flow measurements with radionuclide-labeled particles. Prog Cardiovasc Dis 20:55-79

18. Cotton RB, Lindstrom DP, Kanarek KS, Sundell H, Stahlman MT 1977 Quantitation of cardiac output components in the presence of bidirectional shunts. J Appl Physiol 43:352-356

19. Sandler H, Dodge HT 1968 The use of single plane angiocardiograms for the calculation of left ventricular volume in man. Am Heart J 75:325-334

20. Spach MS, Serwer GA, Anderson PAW, Canent RV Jr, Levin AR 1980 Pulsatile aortopulmonary pressure-flow dynamics of patient ductus arteriosus in patients with various hemodynamic states. Circulation $61: 110-122$

21. Baylen BG, Ogata H, French WJ, Emmanouilides GC 1984 Accurate internal correction for the magnification of cineangiocardiography in infants with congenital heart disease. Am Heart J 107:113-118

22. Erath HD Jr, Graham TP, Smith CW, Thompson SL, Hammon JW 1981 Comparative right and left ventricular volumes and pump function in the newborn lamb. Am J Cardiol 47:855-860

23. Clements JA, Tooley WH 1977 Kinetics of surface-active material in the fetal lung. In: Hodson WA (ed) Development of the Lung. Marcel Dekke, Inc., New York, NY, pp 349-366.

24. Jobe A, Jacobs H, Ikegami M, Jones S 1983 Cardiovascular effects of surfactant suspensions given by tracheal instillation to premature lambs. Pediatr Res $17: 444-448$

25. Rudolph AM, Scarpelli EM, Golinko RJ, Gootman NL 1964 Hemodynamic basis for clinical manifestations of patent ductus arteriosus. Am Heart J 68:447-458

26. McMurphy DM, Heymann MA, Rudolph AM, Melmon KL 1972 Developmental changes in constriction of the ductus arteriosus: responses to oxygen and vasoactive substances in the isolated ductus arteriosus of the fetal lamb. Pediatr Res 66:231-237

27. Friedman WF, Printz MP, Kirkpatrick SE, Hoskins JE 1983 The vasoactivity of the fetal lamb ductus arteriosus in utero. Pediatr Res 17:331-337

28. Oguchi K, Baylen BG, Ikegami M, Jacobs H, Berry D, Jobe A, Emmanouilides GC 1984 Hemodynamic effects of high frequency oscillatory ventilation in preterm lambs. Pediatr Res 17:311(abstr)

29. Fujisawa A, Sasayama S, Takahashi M, Nakamura M, Ohyagi A, Lee J, Yui Y, Kawai C 1984 Enhancement of left ventricular contractility after opening of an arteriovenous fistula in dogs. Cardiovasc Res 18:51-59

30. Sagawa K 1981 The end-systolic pressure-volume relationship of the ventricle: definition, modifications and clinical use. Circulation 63:1223-1227

31. Urschel CW, Covell JW, Sonnenblick EH, Ross J Jr, Braunwald E 1968 Myocardial mechanics in aortic and mitral valvular regurgitation: the concept of instantaneous impedance as a determinant of performance of the intact heart. J Clin Invest 47:867-883

32. Davies P, Dewar J, Tynan M, Ward R 1975 Post-natal developmental changes in length-tension relationship of cat papillary muscles. J Physiol 253:95-102

33. Quinones MA, Gaasch WH, Alexander JA 1976 Influence of acute changes in preload, afterload, contractile state and heart rate on ejection and isovolumic indices of myocardial contractility in man. Circulation 53:293-301

34. Lebowitz EA, Novick JS, Rudolph AM 1972 Development of myocardial sympathetic innervation in the fetal lamb. Pediatr Res 6:887-893

35. Padbury JF, Diakomanolis ES, Hobel CJ, Perelman A, Fisher DA 1981 Neonatal adaptation: Sympathoadrenal response to umbilical cord cutting. Pediatr Res 15:1483-1487

36. Padbury JF, Polk DH, Newnham JP, Lam RW 1985 Neonatal adaptation: Greater sympathoadrenal responses in preterm than term fetal sheep at birth. Am J Physiol 248:E443-449 